\title{
Residual stress and retained austenite in induction hardened ductile iron camshafts
}

\author{
H. Ma ${ }^{1}$, R. J. Bowers ${ }^{1}$, D. O. Northwood ${ }^{1}$, X. $\operatorname{Sun}^{2}$ \& P. J. Bauerle ${ }^{2}$ \\ ${ }^{1}$ Mechanical, Automotive and Materials Engineering, \\ University of Windsor, Ontario, Canada \\ ${ }^{2}$ Chrysler LLC Tech Center, USA
}

\begin{abstract}
Induction hardening is a key manufacturing process in the production of ductile iron automotive camshafts. Its desirable features include low-cost, a wearresistant surface, and ease of manufacturing. Due to the asymmetrical geometry of the camshaft, induction hardening generates non-uniform heating/cooling which leads to a variability in both the microstructure of the surface hardened case, principally the amount of retained austenite (RA), and the level of residual stress (RS). Both RA and RS can affect the contact fatigue performance of the camshaft. In the present study, automotive camshafts containing six lobes per camshaft were induction hardened to different schedules and the RA and RS (surface) variations were determined both between different lobes on the same camshaft and between camshafts that were induction hardened to different schedules. RA and RS measurements were made using x-ray diffraction methods by two independent, certified testing laboratories. Because of their low cost and ease of testing, we have also used optical metallographic methods to determine RA. A correlation was obtained between the RA values obtained by $\mathrm{X}$-ray diffraction with those obtained by optical metallography. This data for ductile iron expands the database that was available for steels to higher carboncontent ferrous alloys. Finally, a correlation is made between RA content and $\mathrm{RS}$ level in order to define a robust process window.
\end{abstract}

Keywords: induction hardening, surface engineering, retained austenite, residual stress, ductile iron, camshafts. 


\section{Introduction}

Ductile iron, previously known as nodular iron or spheroidal-graphite (SG) cast iron, is cast iron in which the graphite is present as nodules. Ductile iron castings are used for many structural applications, particularly those requiring strength and toughness combined with good machinability and low cost [1]. Many applications, such as camshafts, use cast iron because of its good sliding and wear properties, which are in part a result of the free graphite and porosity.

Induction hardening has become increasingly popular in the last several decades, since it has the ability to create high heat intensity very quickly at welldefined locations, which leads to low process cycle times with repeatable quality [2]. Compared to traditional heat treatment sources, induction heating is not only energy efficient but also environmentally friendly, and, as noted by Bhadeshia [3], is likely to become the process of choice for the surface hardening of bearings.

Since the camshafts are quenched in cooling water directly after induction hardening, martensite will form because of the fast cooling rate. However, the martensite finish temperature is usually below the room temperature or the water temperature, so a fully martensitic microstructure will not be obtained. Thus the existence of a noticeable amount of untransformed, or retained, austenite will be unavoidable and a compressive stress will form in the surface of surface hardened materials [3]. Retained austenite can have a significant effect on mechanical properties [4]. From one perspective, it can improve the contact fatigue life in gears and bearings since contact stresses promote decomposition of the retained austenite [5]. From another perspective, it will reduce the surface hardness and decrease the load-carrying capacity and wear resistance but improve the impact strength and toughness [4]. It can also introduce dimensional instability during usage $[3,6,7]$.

There are many techniques that have been used for determining the amount of retained austenite with x-ray diffraction (XRD) and optical metallography being the most widely used. It has been claimed that XRD can measure retained austenite contents greater than $1 \%$ by volume with excellent precision [8]: detection limits as low as $0.5 \%$ have been claimed [4]. However, due to the high cost of XRD equipment, optical metallographic methods have been widely used when the retained austenite content exceeds $10-15 \%$ [4]. There has been much interest in a comparison of the RA data obtained by the two methods [9]. Studies on carburized steels have shown that XRD and automated quantitative optical metallography give similar RA results [10], but other studies on TRIP steels using a wide variety of techniques to determine RA contents, have shown significant differences [11]. There is little data in the literature comparing RA contents in ductile iron obtained using XRD and optical metallography.

In the present study, ductile iron camshafts containing 6 lobes per camshaft were induction hardened to different schedules. Retained austenite and surface residual stress (RS) measurements were made using XRD techniques and the RA content was also determined using a quantitative optical metallographic technique. A correlation is made between the RA content and the RS level. 


\section{Experimental details}

\subsection{Chemical composition of ductile iron}

The chemical composition of ductile iron camshaft was determined using optical emission spectroscopy (OES), and is given in Table 1 .

Table 1: Chemical composition (Wt. \%) of induction-hardened ductile iron.

\begin{tabular}{|l|c|c|c|c|c|c|c|c|c|}
\hline Element & $\mathrm{C}$ & $\mathrm{Mn}$ & $\mathrm{P}$ & $\mathrm{S}$ & $\mathrm{Si}$ & $\mathrm{Cr}$ & $\mathrm{Ni}$ & $\mathrm{Mo}$ & $\mathrm{Cu}$ \\
\hline Wt.\% & 3.63 & 0.81 & 0.010 & 0.004 & 2.14 & 0.04 & 0.03 & 0.02 & 0.93 \\
\hline Element & $\mathrm{Al}$ & $\mathrm{V}$ & $\mathrm{Cb}$ & $\mathrm{Ti}$ & $\mathrm{Co}$ & $\mathrm{Sn}$ & $\mathrm{B}$ & $\mathrm{Mg}$ & $\mathrm{W}$ \\
\hline Wt.\% & 0.010 & 0.004 & 0.006 & 0.006 & 0.004 & 0.066 & 0.0012 & 0.053 & 0.007 \\
\hline
\end{tabular}

\subsection{Induction-hardening parameters}

Induction hardening of the camshafts was performed at a heating parameter of $75 \mathrm{KV}$ and $25 \mathrm{KHz}$ frequency for times from 1.4 to 1.8 seconds. The camshafts were quenched into water. Figure 1 shows the experimental set-up for the induction hardening.

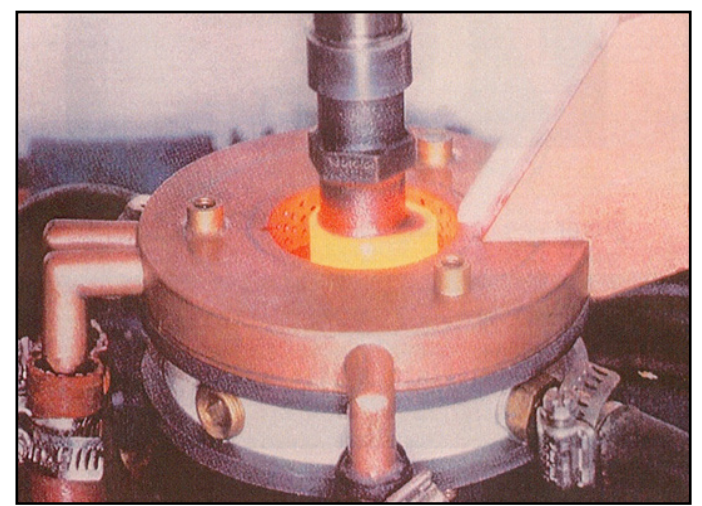

Figure 1: Induction hardening of ductile iron camshaft.

After the induction hardening process, samples were cut from all 18 lobes of the three different camshafts and were marked from A1-A6, B1-B6, and C1-C6. Each lobe was labelled using a black marker with an $\mathrm{X}$ at the same location on the lobe for RA/RS measurements. Figure 2 shows an individual lobe (B2) together with the dimensional measurements. 


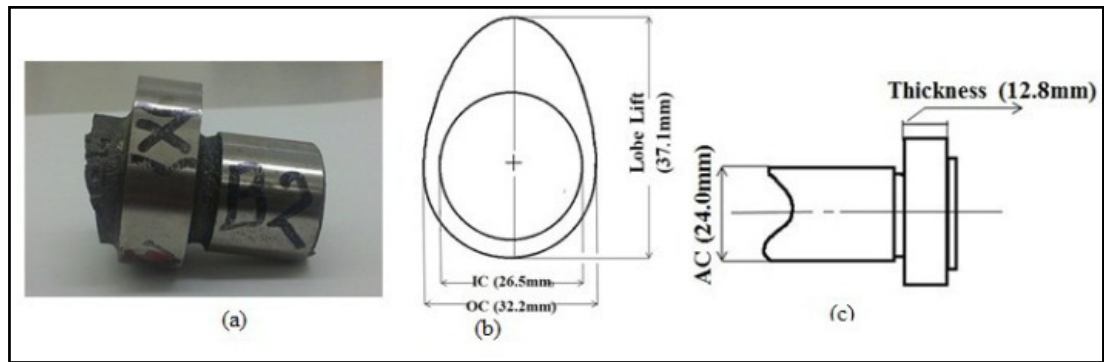

Figure 2: $\quad$ Shape and geometry of camshaft lobe, (a) Sample B2 with mark X to indicate the position for RA and RS measurements; (b) Cam lobe dimensions and geometry; (c) Dimensions and geometry of cam lobe section.

\subsection{Measurement of retained austenite (RA) and residual stress (RS)}

X-ray Diffraction Methods were used to determine the retained austenite (RA) and residual stress (RS) on the surface of the lobe samples. Two independent certified laboratories (Laboratories A and B) were used to make the RA and RS measurements on all samples.

All RS measurements were made according to ASTM Standard E915 [12]. Residual stresses in the cam lobes samples were calculated by measuring the lattice deformation of the $\{211\}$ martensite peak. The x-radiation used was $\mathrm{Cr}$ $\mathrm{K} \alpha$ with a wavelength of $0.2291 \mathrm{~nm}$. The Bragg angle $(2 \theta)$ was set at $156.4^{\circ}$. The relative position of the $\alpha(211)$ peak was measured from $\psi$ angles of $-45^{\circ}$ to $+45^{\circ}$ in $5^{\circ}$ increments in A Laboratory, In Laboratory B, nine different $\Psi$ values were used, namely $0^{\circ}, \pm 25.00^{\circ}, \pm 20.6^{\circ}, \pm 15.85^{\circ}, \pm 3.74^{\circ}$. All the measurements were made using a $1 \mathrm{~mm}$ collimated spot size.

All RA measurements were performed according to the ASTM Standard E975 [13]. "A Four-Peak Method" was used. The relative intensities of $\alpha(200)$, $\alpha(211), \gamma(200)$, and $\gamma(220)$ peaks were measured and RA volume fraction was calculated using Equation (1):

$$
\mathrm{V} \gamma=\frac{\frac{1}{2}\left(\frac{\mathrm{I} \gamma_{(200)}}{\mathrm{R} \gamma_{(200)}}+\frac{\mathrm{I} \gamma_{(220)}}{\mathrm{R} \gamma_{(220)}}\right)}{\frac{1}{2}\left(\frac{\mathrm{I} \gamma_{(200)}}{\mathrm{R} \gamma_{(200)}}+\frac{\mathrm{I} \gamma_{(220)}}{\mathrm{R} \gamma_{(220)}}\right)+\frac{1}{2}\left(\frac{\mathrm{I} \alpha_{(200)}}{\mathrm{R} \alpha_{(200)}}+\frac{\mathrm{I} \alpha_{(211)}}{\mathrm{R} \alpha_{(211)}}\right)}
$$

where the parameter $\mathrm{R}$ is proportional to the theoretical integrated intensity. $\mathrm{R}$ depends on interplanar spacing (hkl), the Bragg angle, $\theta$, crystal structure, and composition of the phase being measured. The $\mathrm{R}$ values used for $\alpha$ (200), $\alpha(211), \gamma(200)$, and $\gamma(220)$ reflections were 150.22, 19.89, 48.86, and 35.07. Figure 3 shows an example of a typical XRD pattern with all the four peaks indicated. 


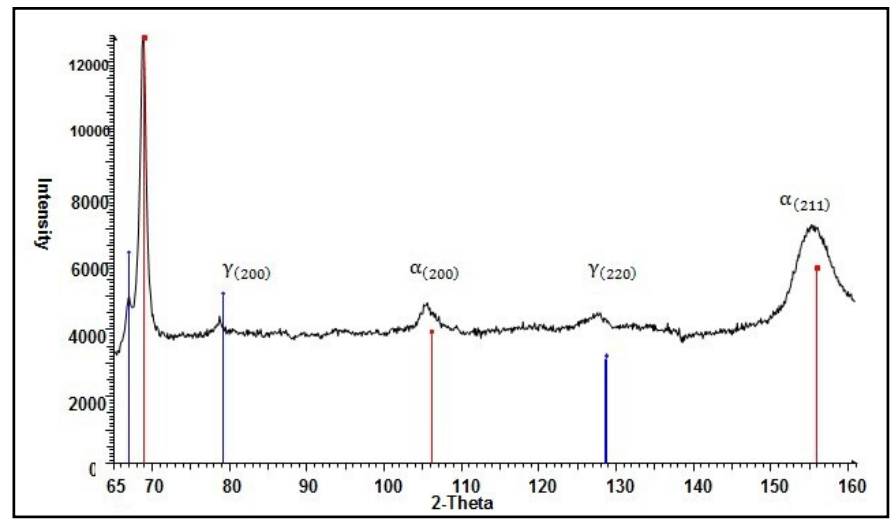

Figure 3: $\quad$ XRD pattern for retained austenite measurements.

\subsection{Optical Metallography}

After the XRD determination of retained austenite and residual stress, samples were cut from the lobes of the designated areas. After hot mounting, a series of $\mathrm{SiC}$ papers were used to rough polish the samples on 240, 320, 400, 600 grit. Intermediate polishing was done with $9 \mu \mathrm{m}$ diamond paste. Fine polishing was done using first $1.0 \mu \mathrm{m}$ and then $0.05 \mu \mathrm{m} \mathrm{Al}_{2} \mathrm{O}_{3}$ powder. The unetched samples were examined to determine the graphite distribution. The microstructure of the as-polished samples showed only nodular graphite, Figure 4. It is clear to be seen that after the image software processing, the colour of graphite changes from black to red, and the ratio of the red part is measured by software according to ASTM Standard E1245[14].
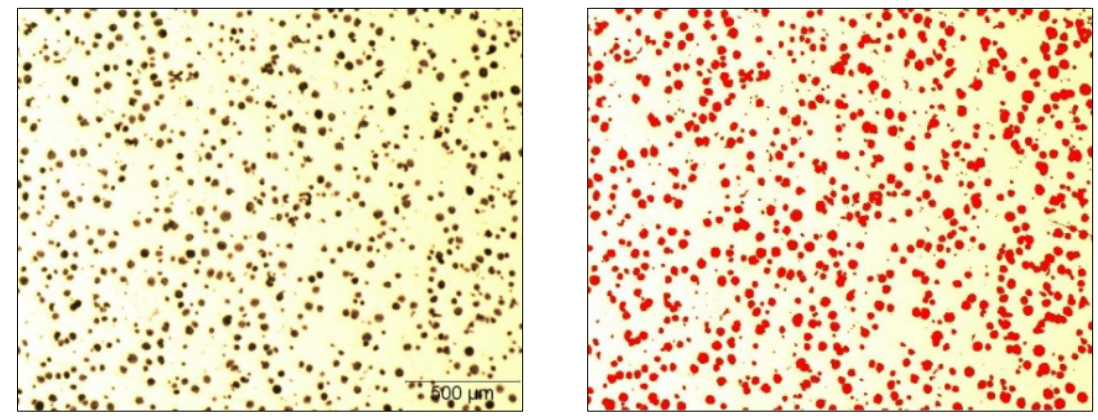

Figure 4: Micrographs showing (a) graphite distribution in the matrix (b) after software processing: the area ratio of the red part in the matrix is calculated.

Then a $2 \%$ Nital etch was used to examine the microstructure. Example microstructures are shown in Figure 5. The microstructure consists of a martensite matrix (yellow-brown), graphite nodules (black) and austenite islands 
(white). The retained austenite usually appears white and is isolated in the martensite matrix. There is a very intense colour difference between the retained austenite and the other phases. It can be seen in Figure 5(b) that only needle-like martensite is present in the retained austenite islands.
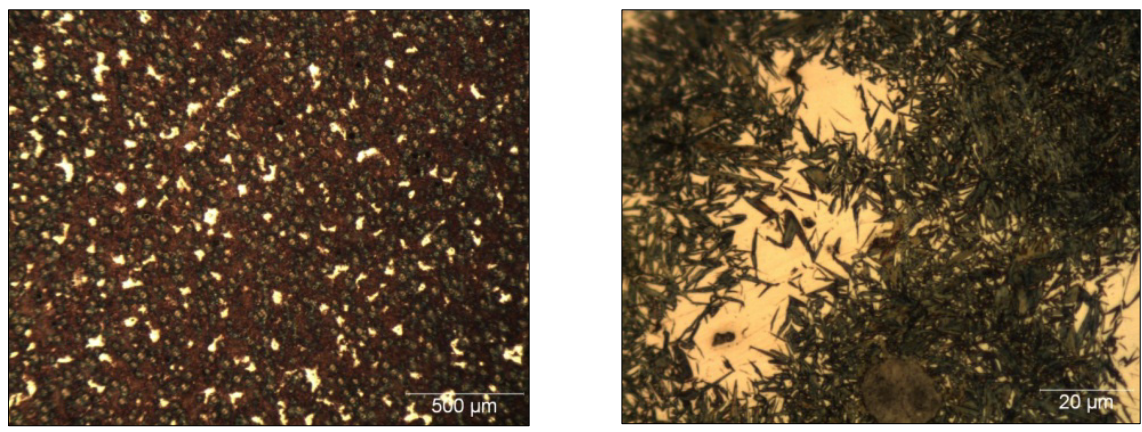

Figure 5: $\quad$ Microstructure of induction hardened cam lobe (a) 50X (b) 1000X.

In order to determine the amount of retained austenite, a Buehler Omnimet Imaging Analysis Software was employed. Ten micrographs at 200X magnifications were used for each sample and an average value was calculated. The software used conformed to ASTM Standard E1245 [14]. The software detects microconstituents whiter than a defined threshold level. In this case it is relatively easy to define a threshold because of the intense colour difference between the retained austenite (white) and the martensite (grey).

\section{Results and discussion}

\subsection{Graphite content}

Table 2 shows the graphite content for all 18 samples including average values.

Table 2: $\quad$ Graphite content of 18 samples by image analysis.

\begin{tabular}{|l|l|l|l|l|l|}
\hline Sample & $\begin{array}{l}\text { Graphite } \\
\text { Content } \%\end{array}$ & Sample & $\begin{array}{l}\text { Graphite } \\
\text { Content \% }\end{array}$ & Sample & $\begin{array}{l}\text { Graphite } \\
\text { Content \% }\end{array}$ \\
\hline A1 & $11.74 \pm 0.4$ & B1 & $12.34 \pm 0.3$ & C1 & $10.58 \pm 0.4$ \\
\hline A2 & $10.1 \pm 0.5$ & B2 & $12.76 \pm 0.4$ & C2 & $9.64 \pm 0.3$ \\
\hline A3 & $11.18 \pm 1.0$ & B3 & $12.46 \pm 0.7$ & C3 & $9.8 \pm 0.5$ \\
\hline A4 & $11.42 \pm 0.5$ & B4 & $12.82 \pm 0.5$ & C4 & $10.32 \pm 1.5$ \\
\hline A5 & $11.4 \pm 1.1$ & B5 & $10.39 \pm 0.3$ & C5 & $9.7 \pm 1.2$ \\
\hline A6 & $10.86 \pm 0.6$ & B6 & $9.76 \pm 0.5$ & C6 & $9.46 \pm 0.2$ \\
\hline A(Aver) & 11.1 & B(Aver) & 11.7 & C(Aver) & 9.9 \\
\hline
\end{tabular}


Ten images were used for each sample and an average value has been calculated. Although they would all have the same chemistry, there are differences both from lobe to lobe on the same camshaft and from camshaft to camshaft. Overall, camshaft $\mathrm{C}$ had the lowest graphite content.

\subsection{Retained austenite measurements}

Figure 6 shows the microstructure of an etched sample and its image analysis.
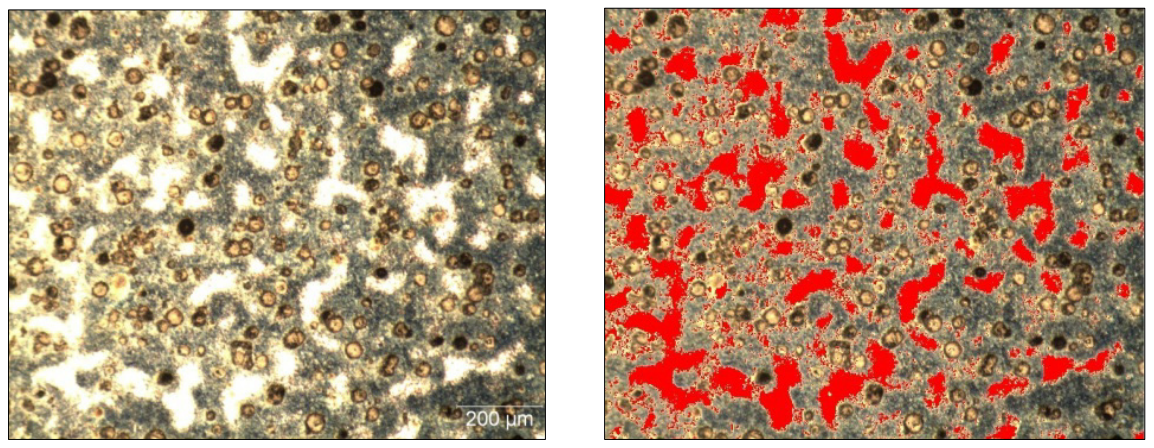

Figure 6: Retained austenite determination: (a) image: 2\% Nital etching (b) image analysis.

Table 3 shows the retained austenite content of all the 18 samples, it can be seen that there are significant differences between samples.

Table 3: $\quad$ Retained austenite (RA) contents of 18 samples by OM and XRD.

\begin{tabular}{|c|c|c|c|c|c|c|c|c|c|c|c|}
\hline \multirow{3}{*}{ Lobe } & \multicolumn{3}{|c|}{ RA Content $\%$} & \multirow{3}{*}{ Lobe } & \multicolumn{3}{|c|}{ RA Content $\%$} & \multirow{3}{*}{ Lobe } & \multicolumn{3}{|c|}{ RA Content \% } \\
\hline & \multirow[t]{2}{*}{$\mathrm{OM}$} & \multicolumn{2}{|c|}{ XRD } & & \multirow[t]{2}{*}{$\overline{\mathrm{OM}}$} & \multicolumn{2}{|c|}{ XRD } & & \multirow[t]{2}{*}{$\mathrm{OM}$} & \multicolumn{2}{|c|}{ XRD } \\
\hline & & A & B & & & $\mathrm{A}$ & $\mathrm{B}$ & & & A & B \\
\hline A1 & 13.3 & 12.0 & 17.7 & B1 & 15.1 & 23.0 & 22.6 & $\mathrm{C} 1$ & 11.7 & 15.0 & 20.9 \\
\hline $\mathrm{A} 2$ & 15.7 & 14.0 & 19.8 & B2 & 12.9 & 19.0 & 26.5 & $\mathrm{C} 2$ & 12.8 & 17.0 & 18.0 \\
\hline A3 & 14.2 & 14.0 & 20.6 & B3 & 12.7 & 19.0 & 24.9 & C3 & 12.0 & 18.0 & 21.6 \\
\hline A4 & 14.2 & 13.0 & 17.6 & B4 & 19.1 & 23.0 & 34.7 & $\mathrm{C} 4$ & 11.3 & 17.0 & 23.8 \\
\hline A5 & 15.5 & 16.0 & 22.9 & B5 & 13.7 & 18.0 & 23.7 & $\mathrm{C} 5$ & 12.8 & 16.0 & 22.1 \\
\hline A6 & 14.4 & 14.0 & 24.1 & B6 & 10.1 & 18.0 & 26.2 & C6 & 11.5 & 15.0 & 18.5 \\
\hline
\end{tabular}


Figure 7 shows representative images for retained austenite contents at the low $(7.5 \%)$ and high $(26.5 \%)$ ranges for the camshaft. The differences in retained austenite content could be due to the non-uniform heating in the induction hardening process. Different lobes might reach different temperatures before the camshafts were quenched, resulting in differences in retained austenite.
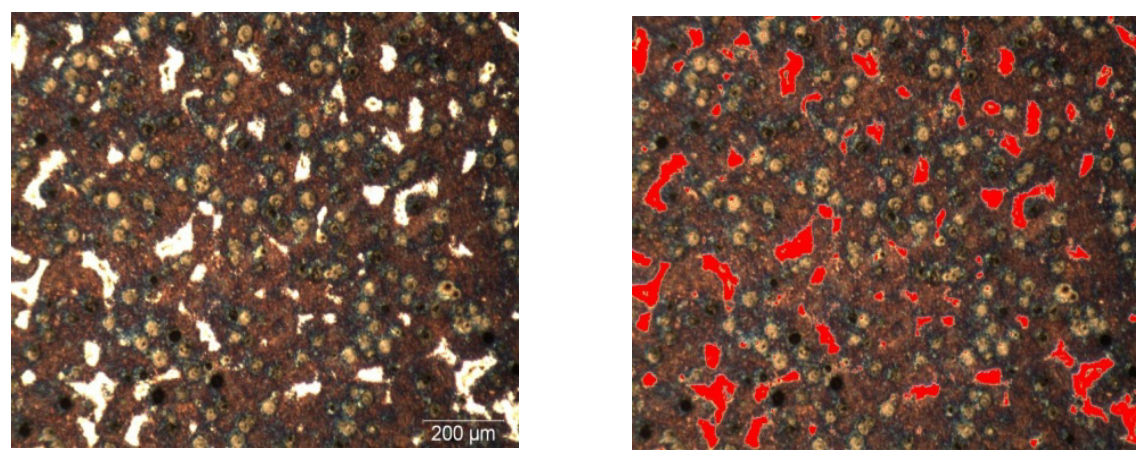

(a) Retained austenite content $7.5 \%$
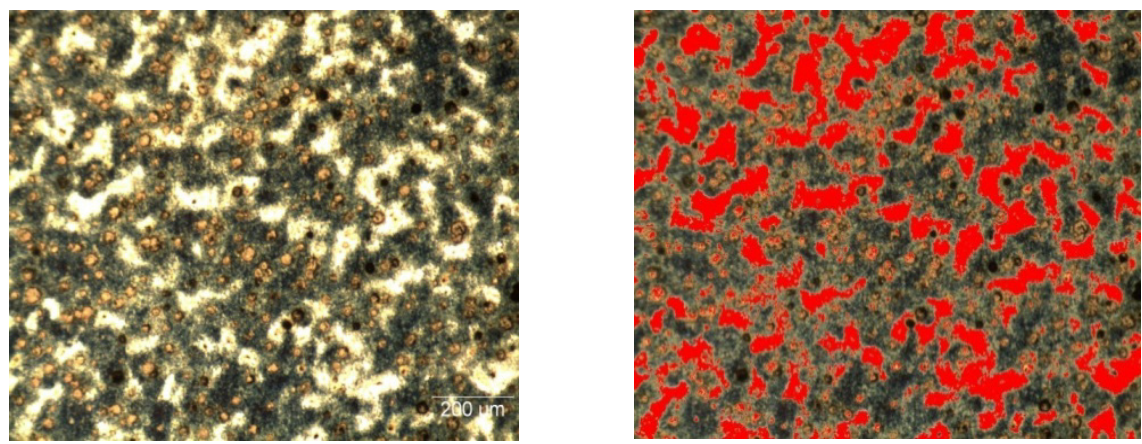

(b)Retained austenite content $26.5 \%$

Figure 7: Image analysis shows that these samples have different volume fraction of retained austenite, varying from $7 \%$ to $27 \%$.

\subsection{Relationship between RS (XRD) and RA (XRD)}

The general relationships between RS (XRD) and RA (XRD) is given in Figures 8(a) and (b) for Laboratories A and B, respectively. It can be seen that for all the samples, the "surface" residual stresses are compressive. Laboratory B results show a higher RA and compressive RS when compared to those for Laboratory A. Initially, the residual compressive stress increases with an increasing amount of retained austenite, reaching a maximum value, then decreases with the RA increasing and reaches a maximum. It should be noted that the measured value of residual stress is only for a surface layer $(\sim 10 \mu \mathrm{m}$ in depth) and the residual stress would vary with depth into the core of the camshaft [3]. 


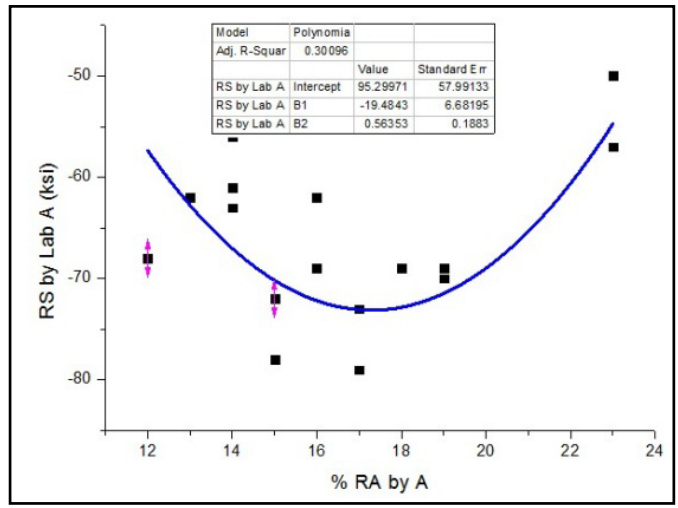

(a) RA vs RS for Laboratory A

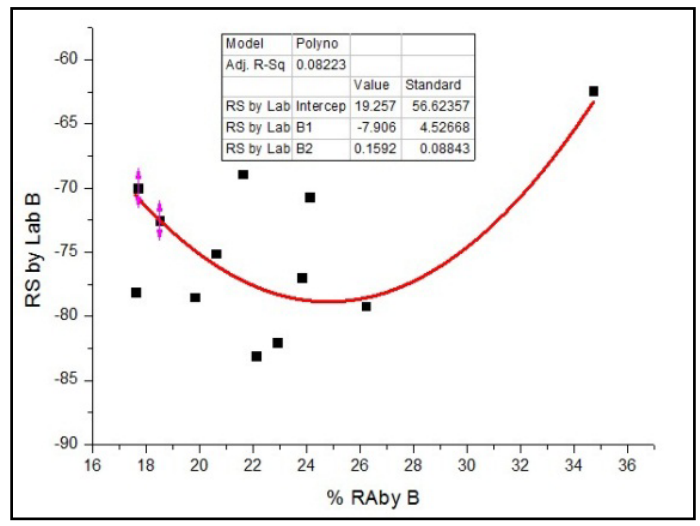

(b) RA and RS for Laboratory B

Figure 8: Relationships between RA (XRD) and RS (XRD) for (a) Laboratory A (b) Laboratory B.

\subsection{Relationship between RS (XRD) and RA by optical microscopy}

Using the retained austenite values obtained in our laboratory by image analysis, the relationship between RA (OM) and RS (XRD) can be determined and is shown in Figure 9. There is an approximately linear relationship between the compressive residual hoop stress and the RA content as measured by the OM. The magnitude of the compressive stress decreases with increasing RA content. Such a relationship was only obtained for the RS (XRD) data from Laboratory A.

\subsection{Relationship between RA values obtained from OM and XRD}

The relationship between RA (XRD) and RA (OM) is shown in Figure 10. It can be seen that RA (XRD) is generally higher than RA (OM). This may be due to 


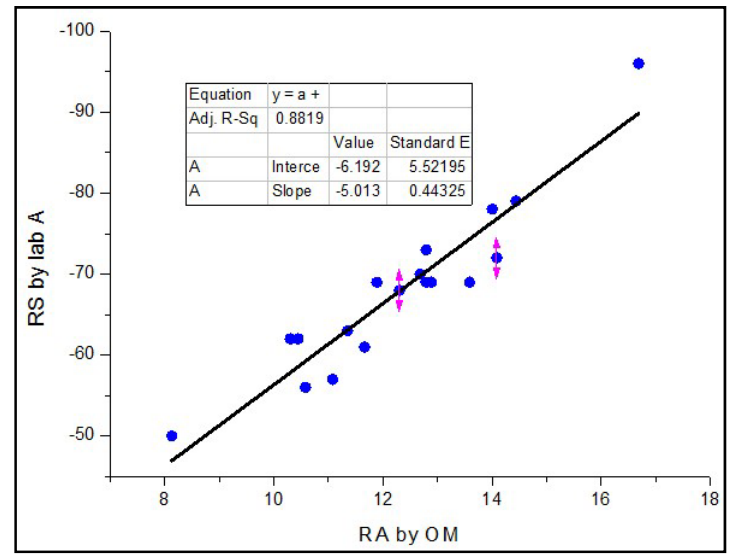

Figure 9: The relationship between RS (XRD) and RA (OM) for RS data obtained in Laboratory A.

the fact that some of the "white" retained austenite is "hidden" within the black martensite matrix in the micrographs and is not picked up in the image analysis (is below the white threshold). The RA (XRD) values given in Figure 10 are calculated without taking the graphite nodules into account.

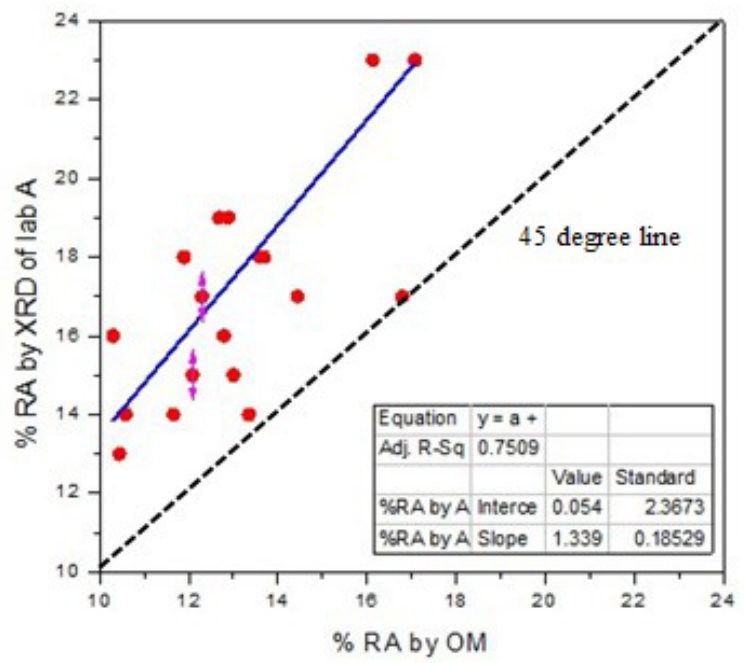

Figure 10: Relationship between RA (XRD) and RA (OM).

Equation (1) can be modified to take into account the volume fraction of graphite: see Equation (2). 


$$
\mathrm{V} \gamma=\left(1-\mathrm{V}_{\text {graphite }}\right) \cdot \frac{\frac{1}{2}\left(\frac{\mathrm{I} \gamma_{(200)}}{\mathrm{R} \gamma_{(200)}}+\frac{\mathrm{I} \gamma_{(220)}}{\mathrm{R} \gamma_{(220)}}\right)}{\frac{1}{2}\left(\frac{\mathrm{I} \gamma_{(200)}}{\mathrm{R} \gamma_{(200)}}+\frac{\mathrm{I} \gamma_{(220)}}{\mathrm{R} \gamma_{(220)}}\right)+\frac{1}{2}\left(\frac{\mathrm{I}\left(_{(200)}\right.}{\mathrm{R} \alpha_{(200)}}+\frac{\mathrm{I} \alpha_{(211)}}{\mathrm{R} \alpha_{(211)}}\right)}
$$

where $\mathrm{V}_{\text {graphite }}$ is the volume fraction of graphite that we have determined from OM image analysis. Figure 11 is a revised plot of RA (XRD) vs. RA (OM), where RA (XRD) is calculated using Equation (2). Although the values are now closer to the RA $(X R D)=R A(O M)$ line, $\mathrm{RA}(\mathrm{XRD})$ are still higher than $\mathrm{RA}(\mathrm{OM})$. As already noted, it is believed that this is because of an inability to identify the retained austenite in a mixed-microstructure (typically martensite-austenite).



Figure 11: RA (XRD), as calculated using Equation (2), as a function of RA (OM).

\section{Conclusions}

Due to non-uniform heating with induction hardening of ductile iron, together with the volume expansion from the martensite transformation on cooling, different levels of surface residual stress are formed. This also results in a range of retained austenite contents from $10 \%$ to roughly $30 \%$ (as determined by XRD) in these induction hardened camshafts.

X-ray diffraction was used as a method to determine the retained austenite and residual stress in ductile iron samples. Different values of RA and RS were obtained by two different Laboratories. Equation (1) which is taken from ASTM Standard E975 cannot be used directly in the retained austenite measurement for ductile iron samples, because the volume fraction of nodular graphite is not accounted for. We have used optical microscopy to determine the value of $\mathrm{V}_{\text {graphite. }}$ This value has been incorporated into the ASTM Standard E975 procedure to obtain a corrected RA (XRD) value (Equation (2)).

Optical microscopy, which is a low cost and convenient method, was also used to determine the RA content. A relationship has been established between 
the surface RS (XRD) and RA (OM) where a lower RA content ( 11\%) leads to a higher compressive RS than for RA contents of up to $20 \%$.

\section{Acknowledgements}

This work was supported by the Powertrain Materials Engineering Department of Chrysler LLC and the Natural Science and Engineering Research Council of Canada (NSERC).

\section{References}

[1] Lyle. R. Jenkins and R. D. Forrest, Ductile Iron, Properties and Selection: Irons, Steels, and High-Performance Alloys, Vol 1, ASM Handbook, ASM International, Materials Park, OH, U.S.A., pp. 33-55, 1990.

[2] V. Rudnev, D. Loveless, R. Cook and M. Black, Handbook of Induction Heating, Marcel Dekker Inc, New York, U.S.A., pp. 11-14, 2003.

[3] H. K. D. H. Bhadeshia, Steel for bearings, Progress in Materials Science, Vol. 57, pp. 268-435, 2012.

[4] Daniel H. Herring, A discussion of retained austenite, Industrial Heating, Vol. 72, no.3, pp 14-16, March 2005.

[5] B. B. Vinokur and A. L. Geller, The effect of retained austenite on contact fatigue in Cr-Ni-W carburized steel, JOM Journal of the Minerals, Metals and Materials Society, Vol 49, no.9, pp. 69-71, 1997.

[6] C. F. Jatczak, J. A. Larson, and S. W. Shin, Retained Austenite and Its Measurements by X-ray Diffraction, Society of Automotive Engineers, Inc., Warrendale, PA, U.S.A, pp. 1-55, 1980.

[7] V. M Zinchenko, B. V. Georgievskaya, and V. A. Olovyanishnikov, Effect of residual austenite on the mechanical properties of carburized steels, Metal Science and Heat Treatment, Vol. 9, no. 11-12, pp. 919-925, 1987.

[8] T. Gnäupel-Herold and A. Creuziger. Diffraction study of the retained austenite content in TRIP steels. Materials Science and Engineering: A, Vol. 528, no.10-11, pp. 3594-3600, 2011.

[9] B. L. Bramfitt, Arlan O. Benscoter, Metallographer's guide: practices and procedures for irons and steels, ASM International, Materials Park, $\mathrm{OH}$, U.S.A., pp. 88-151, 2002.

[10] George T. Eldis, Correlation of measurements of retained austenite in carburized steels by X-Ray diffraction and quantitative metallography, Journal of Heat Treating, Vol. 1, no 3, pp. 3-25, 1980.

[11] P. J. Jacques, S. Allain, O. Bouazi et al. On measurement of retained austenite in multiphase TRIP steels: Results of blind round robin test involving six different techniques, Materials Science and Technology, Vol. 25, No. 5, pp 567-574, 2009.

[12] "ASTM E915-10 Standard Test Method for Verifying the Alignment of XRay Diffraction Instrumentation for Residual Stress Measurement”, ASTM International, West Conshohocken, PA, U.S.A., 2010. 
[13] “ASTM E975-03 Standard Practice for X-Ray Determination of Retained Austenite in Steel with Near Random Crystallographic Orientation", ASTM International, West Conshohocken, PA, U.S.A., 2008.

[14] "ASTM E1245-03 Standard Practice for Determining the Inclusion or Second-Phase Constituent Content of Metals by Automatic Image Analysis", ASTM International, West Conshohocken, PA, U.S.A., 2008. 